07.12 .2017

Professor Brian McGill,

Editor in Chief

Global Ecology and Biogeography

Dear Prof. McGill,

We attach a revised version of our manuscript 'Inconsistent patterns of body size evolution in co-occurring island reptiles' (Ref. GEB-2017-0100; title modified according to referee's suggestion). The manuscript was reviewed by a new anonymous referee and the Editor, Dr. Ana Santos, added her own comments. We were happy to see the supportive review and thanks the editor and the referee for their important suggestions. We followed most of these and revised the manuscript accordingly. Below please find a point by point description of how we dealt with each comment. We hope you will find our manuscript is now at level and ready for publication in Global Ecology and Biogeography.

Sincerely,

Yuval Itescu on behalf of all authors

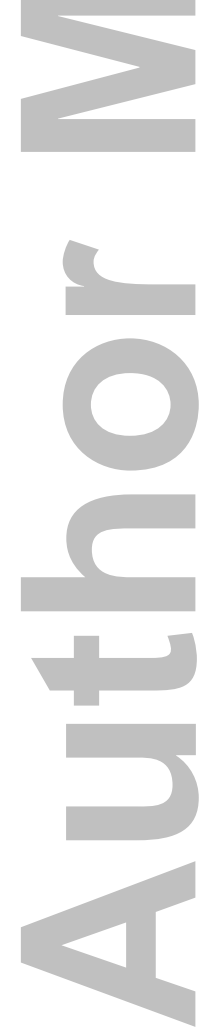

This is the author manuscript accepted for publication and has undergone full peer review but has not been through the copyediting, typesetting, pagination and proofreading process, which may lead to differences between this version and the Version of record. Please cite this article as doi:10.1111/ geb.12716. 


\title{
EDITOR'S COMMENTS TO AUTHORS
}

\author{
Editor: Santos, Ana
}

Comments to the Author:

First, I want to apologize for the delay in the editorial process. Sometimes it takes longer that we would like to, as it happened with your manuscript.

Your manuscript was evaluated by a referee that was not involved in the first round of reviews. I share his view of your paper, and I think it has improved greatly since your previous submission. This new reviewer suggests that you use and AIC based model selection. I think this is a good suggestion and it would strengthen your results, but I will leave it up to you to decide if you should include these analyses in the manuscript. What I strongly advise you to do is to follow his suggestion of highlighting more your general conclusions that the island rule is not universal.

We thank the editor for her supporting comments. As we specify below, we included AICc scores in a new appendix and highlighted in the abstract and in the concluding paragraph of the discussion that our results contrast the generality theory of size evolution on islands.

Dr. Ana Santos, Editor

\section{REVIEWER COMMENTS TO AUTHORS}

Referee: 1

Comments to the Author

Referee: 2

Comments to the Author

This is a nice work. I didn't get to review the first round, but this version seems robust an straightforward, so to me it was a good decision to eliminate the additional analyses on the species with more data. I've got two significant comments, and a few small ones.

To me the lack of general predictive power of your predictors over all species is the most important result, so I'm really glad you chose to put this in front and make a paper about the lack of general "island rules". By highlighting that responses differ among species rather than trying to explain each species separately based on correlations you make a great job, so I'm $100 \%$ in line with the importance of the paper and its timeliness. That is why I think you should highlight it a bit more, tweaking the text to put such heterogeneity in front, e.g. in the title, where I use "Heterogeneous" or "Non coherent" rather than "Divergent". Similarly, in the abstract the main conclusions need to start a straightforward sentence saying something like "There are no universal drivers of body size evolution on Aegean reptiles." And also that "this rejects/contradicts former theory". Some of this rewording is needed also in the discussion, although very little. In particular, you need to stress that you are rejecting former theory in the last paragraph, as part of your take-home message. 
Thanks for this suggestion. We changed the text according to it.

To me the main problem remaining in the text is model selection. Although I would agree with you in that your selection of models based on R2 scores provides sound insights on the lack of general drivers, so the conclusions will stand out, I found the reasoning not to use AIC scores a bit unconvincing. Since I'm not a biostatistician I could certainly live with it, but after reading your response to Diniz-Filho I wonder whether you used AIC in the correct way, for it penalizes the amount of variables in the model. And AICc scores are particularly suited for datasets with low sample size, as some of yours are. Here, the pick would be to compare models according to their Akaike weight; that is, the probability that a particular model is the most informative. I'm sure you'll have models with, say, 20 or $30 \%$ probability competing as the best model for several species. Anyway, I think you shouldn't abandon the information approach so quickly, and provide AICc results in the supplement, although perhaps not the raw results, which I concur, would be confusing.

As we stated in the text (and in the reply to referees in the previous round of revision), we are not comfortable with relying on AIC (or even AICc) scores to determine which model is the most informative, and Mac Nally et al.'s recent paper (Journal of Applied Ecology, 2017, “Model selection using information criteria, but is the 'best' model any good?"

http://onlinelibrary.wiley.com/doi/10.1111/1365-2664.13060/abstract) clearly and compellingly explains why: first, the model with the lowest AIC may simply be the best of a group of noninformative models (like the best of infectious diseases - you still do not want it), and second, the penalty AIC applies to adding additional parameters (2) is too modest. We now cite this paper in the text. We also added a paragraph of discussion regarding this point as we think our results serve as a good example for why to prefer $\mathrm{p}$-value based model selection over information criteria based model selection for studies such as ours. Nevertheless, we accept the referee's suggestion to let the readers get our impression themselves, and now present AICc scores of the best models $(\triangle \mathrm{AICc} \leq 2)$ for each species in a new supplementary file.

To me the most compelling of your results, and actually the real reason why a frequentist approach is sound here, is your meta-analysis. So why not doing something similar based on AIC weights? AIC scores are not comparable among models based on different datasets, but AIC weights are if the same parameters are tested, so why not just summing all AIC weights per predictor across all species? Here the total weight of a predictor for a species it would be the sum of the AICw of all models where it is present. Given that all models are tested for AICw, the closer to 1 , the more informative a variable is. And across all species, the closer to 16, the closer it is to be a general predictor, informative regardless of the species. I think I can hear you saying "but we have showed that with the meta-analysis", but I can also hear other readers saying "but they use R 2 s! Surely there would be general patterns if they had used AICs". So I still find quite useful to show that results are consistent across analytical paradigms. What this approach certainly does not provide is a pick on the homogeneity signs of the relationships, it just tells you about how often it is informative. But your work will be more trustworthy if it includes similar results from a different approach. 
We thank the referee for this suggestion but think that using AIC weights to show what we have shown in the meta-analysis is somewhat confusing, especially since, as the referee rightly mentions, it provides no information about the direction of the effect of the predictor. Therefore, although we do show the AICc based models in Appendix 5, we prefer not to include the AIC weights analysis.

Besides that I have little to say. I really think that the decision of leaving out the more detailed analyses on a few species is sound. The current work is clear and straightforward, and stands out as a valuable contribution for GEB in my opinion, and these other analyses can be published elsewhere.

Some minor comments follow:

Abstract. In the methods you don't tell which kind of analyses you use.

Now added.

In line 52 I'd substitute "We analyse" for "We use linear models and meta-analyses to determine which predictors are more informative, analysing the data for all reptiles..."

Sentence rephrased.

Line74. To be certain, here you refer to MacArthur \& Wilson's Equilibrium Theory of Island Biogeography (ETIB). Currently island biogeography theory (ibt) includes many other topics, such as, e.g., that habitat heterogeneity within the island also increases species richness, to mention one you may be familiar with, or that increasing isolation and area determine a radiation zone where cladogenesis starts to be more important than anagenesis. No need to cite these latter theories, just rephrase and mention ETIB rather than just ibt.

We actually want to emphasize only the depauperate nature of islands, rather than point to any (often contentious) mechanism, so we added a citation for Darlington (1957) and retain just the citation for the 1963 paper of MacArthur and Wilson, rather than the more inclusive 1967 book

L242-243. Please show these results (as supplementary material), and rephrase this sentence (it is grammatically incorrect)

We now realized that the sentence as we originally phrased it may be a bit misleading: differences between males and females in their response to single predictors do exist in some of the study species, but our general conclusion, that different factors affect body size in different species, is maintained even if we test only females or only males. Since we want to avoid any confusion by our readers, and since the inter-sexual differences in body size evolution are not the focus of this study (but perhaps an interesting study question in its own right), but rather the interspecific differences, we omitted the sentence from the text.

L366. I'd start this paragraph with "Strikingly" or similar, to highlight your most important result (see my first comment). 
We thank the referee for this suggestion, but we think that specifically here it is not appropriate to use "strikingly" or other such strong wording, as we are not the first that failed supporting Heaney's prediction.

L483-486. Rephrase this sentence, it is fragmentary and difficult to read. I probably can make out for 2 or 3 separate sentences.

\section{Done.}

Figures 2 and 3. Please put variable names in the $\mathrm{Y}$ axes, so the reader does not have to jump continuously to the caption to understand the figure.

The names of the variables on the Y axes are now clearly marked in figures $2 \& 3$.
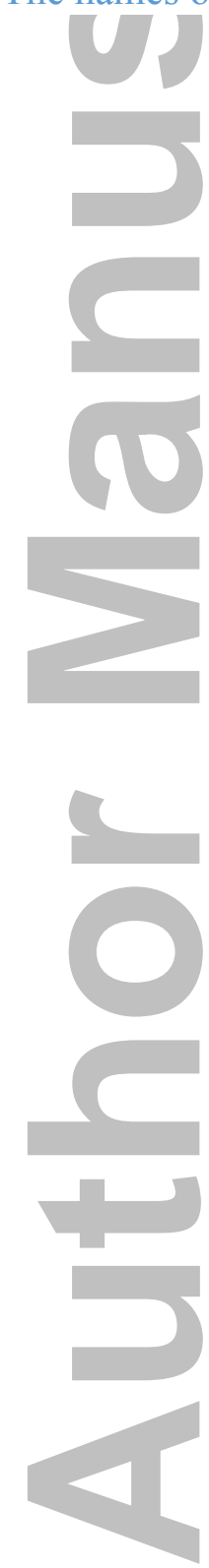


\section{Inconsistent patterns of body size evolution in co-occurring island reptiles.}

Yuval Itescu1 (yuvitescu@gmail.com), Rachel Schwarz ${ }^{1}$

(rachelschwarz13@gmail.com), Colin Donihue²(colin_donihue@fas.harvard.edu), 4

Alex Slavenko (slavenko@mail.tau.ac.il), Stephanos A. Roussos ${ }^{3,4}$

D. Valakos ${ }^{6}$ (evalakos@biol.uoa.gr), Johannes Foufopoulos ${ }^{7}$ (jfoufop@umich.edu),

Panayiotis Pafilis ${ }^{6}$ (ppafil@biol.uoa.gr), Shai Meiri ${ }^{1}$ (uncshai@post.tau.ac.il)

${ }^{1}$ School of Zoology, Tel Aviv University, Tel Aviv 6997801, Israel

${ }^{2}$ Department of Organismic and Evolutionary Biology, Harvard University,

Cambridge, MA 02138, USA

${ }^{3}$ Department of Biological Sciences, University of North Texas, Denton, TX 76203,

${ }^{4}$ Department of Biological Sciences, Texas Tech University, Lubbock, TX 79409, USA

${ }^{5}$ School of Biological and Chemical Sciences, Queen Mary University of London,

London E1 4NS, UK

${ }^{6}$ Department of Biology, National and Kapodistrian University of Athens, Athens 157-

84, Greece

${ }^{7}$ School of Natural Resources and Environment, University of Michigan, Ann Arbor,

Key words: body size, competition, island area, isolation, lizards, predation, snakes. 
Corresponding Author: Yuval Itescu, Department of Zoology, Tel Aviv University,

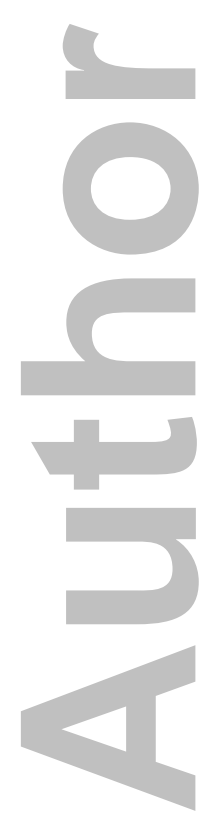


Aim Animal body sizes are often remarkably variable across islands, but despite

much research we still poorly understand both patterns and drivers of body-size

evolution. Theory predicts that interspecific competition and predation pressures are

relaxed on small, remote islands, and that these conditions promote body-size

evolution. We studied body size variation across multiple insular populations of 16

reptile species co-occurring in the same archipelago and tested which island

characteristics primarily drive body-size evolution, what the common patterns are,

and whether co-occurring species respond similarly to insular conditions.

Location Aegean Sea islands.

Time period 1984-2016.

Major taxa studied Reptiles.

Methods We combined field work, museum measurements, and a comprehensive

literature survey to collect data on nearly 10,000 individuals representing eight lizard

and eight snake species across 273 islands. We also quantified a large array of

predictors to directly assess the effects of island area, isolation (both spatial and

temporal), predation and inter-specific competition on body size evolution. We used

linear models and meta-analyses to determine which predictors are informative for all 
Results Body size varies with different predictors across the species we studied, and 55 patterns differ within families and between lizards and snakes. While each predictor 56 influenced body size in at least one species, no general trend was recovered. As a group, lizards are hardly affected by any of the predictors we tested, whereas snake size generally increases with area, competitor and predator richness, and decreases with isolation.

Main conclusions No factor emerges as a predominant driver of Aegean reptile sizes.

This contradicts theories of general body-size evolutionary trajectories on islands. We conclude that overarching generalizations over-simplify patterns and processes of
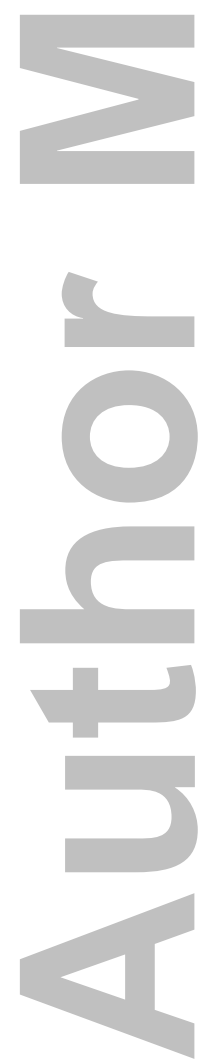


\section{INTRODUCTION}

Identifying general pathways in the evolution of body size variation among insular

populations has received decades of attention, and multiple patterns and drivers have

been proposed and contradicted. Trait evolution on islands is often perceived as

strong, predictable and consistent across taxa (Van Valen, 1973; Lomolino, 2005;

Köhler et al., 2008). The most debated pattern is the "island rule", suggesting insular

animals tend to evolve a medium body size (Van Valen, 1973; Lomolino, 2005;

Faubry \& Svenning, 2016 cf. Meiri, 2007; Itescu et al., 2014; Leisler \& Winkler,

2015Insular faunas are generally depauperate, becoming species-poor as islands

become smaller and more isolated (e.g., Darlington, 1957; MacArthur \& Wilson,

1963). Therefore, insular animals are thought to experience relaxed interspecific

competition and predation pressures, which, in turn, promote higher population

densities and consequently stronger intraspecific competition (Melton, 1982).

Together with resource limitation, these ecological processes are commonly thought

to drive body size evolution on islands (Case, 1978; Melton, 1982; Lomolino, 2005).

Heaney (1978) suggested that the effect of each of these factors changes with the size

of the focal island and animal. He hypothesized that interspecific competition is more

important to large animals than to small ones. He also hypothesized that the effect of

predation is equally important at all sizes, but produces different trends at different

body sizes. Additionally, he hypothesized that food limitation is the most important

selection agent on small islands, predation on medium-sized islands, and interspecific 
size, via direct selection on life history traits, have also been proposed (Adler \&

Levins, 1994; Palkovacs, 2003).

Area and isolation are the two main island characteristics thought to affect animal

body size. Lomolino (2005) suggested that small species increase in size on smaller

and more isolated islands while large species become smaller on such islands. Other

studies, however, found minor support for such relationships in mammals (Meiri et

al., 2005, 2006), snakes (Boback, 2003), and lizards (Meiri, 2007). Heaney (1978)

predicted the body size of small mammals decreases while that of large mammals

increases with increasing area (see also Melton, 1982; Marquet \& Taper, 1998). He

99

further predicted that medium sized animals are largest on intermediate-sized islands,

et al. (2005) found no support for Heaney's prediction, or for a linear response of size

to island area.

Isolation can be defined both in space and in time. Spatial isolation, usually calculated as island distance from the nearest mainland (e.g., Anderson \& Handley, 2002, Meik

et al., 2010), reduces immigration (i.e., gene flow) rates and makes in situ adaptations

more likely (Heaney, 2000). The effect of spatial isolation on body size is possibly indirect, reflecting factors such as predation and competition pressures (Heaney,

1978; Arnold, 1979). Anderson \& Handley (2002) suggested that, where over-water

dispersal is unlikely (as in the case of Aegean Sea reptiles, Foufopoulos \& Ives,

1999), body sizes on close and far islands would not differ. Temporal isolation is

thought to be associated with body size in systems where sufficient time since

isolation has not yet passed to allow a unidirectional change towards an optimum to 
recently isolated islands has also been suggested (Aubret, 2015). As increased

isolation is expected to drive the same phenotypic changes as decreasing island area

(Adler \& Levins, 1994), Heaney's (1978) prediction for island area is possibly true for

isolation as well (i.e., that intermediate-sized species are smallest at intermediate

isolation, and larger at low and high degrees of isolation). Furthermore, as Heaney

suggested, island area reflects predation and interspecific competition and therefore

the pattern suggested for island area should apply to predation and interspecific

competition, with the later possibly showing a stronger effect in small species.

Reptiles are well-known for their extreme-sized insular forms: giant tortoises and

Komodo dragons on one hand, and the world's smallest lizards (Sphaerodactylus

snakes (Caribbean Tetracheilostoma threadsnakes; Hedges, 2008) on the other.

Whether reptile body sizes tend to grow or diminish on islands compared to the

mainland seems to be a clade-specific characteristic (see e.g., Case, 1978; Boback \&

Guyer, 2003; Meiri, 2007, 2008). How island area and isolation affect reptile body

size evolution is unclear. Previous studies provided inconsistent results (cf. Soulé,

1966; Hasegawa \& Moriguchi, 1989; Boback, 2003; Meiri, 2007; Meik et al., 2010;

Donihue et al., 2016). Release from predation is thought to drive size increase in small

species and size decrease in large species by relaxing direct selection on size-related

anti-predatory adaptations (Heaney, 1978; Vervust et al., 2007). Relaxed interspecific

competition allows niche shifts and promotes size changes (Soulé, 1966; Schoener,

1970; Case, 1978; Hasegawa, 2003; but see Dunham et al., 1978). Ecological release

(both from predators and interspecific competitors) is also thought to promote higher 
sizes, although smaller size is expected where early maturity is advantageous (Melton,

1982; Palkovacs, 2003).

To date, insular reptile body size evolution studies either contrasted mainland and

island species or populations (e.g., Case, 1978; Boback \& Guyer, 2003; Meiri, 2007;

Itescu et al., 2014), or examined the effects of some predictors across populations of a

single species (e.g., Soulé, 1966; Meik et al., 2010) or genus (Dunham et al., 1978). It

remains unclear which island characteristics primarily drive body size evolution, what

the common patterns are, and whether co-occurring species respond similarly to

insular conditions. Which factor is most influential is sometimes debated even for a

single species (cf. Calsbeek \& Cox, 2010, 2011; Losos \& Pringle, 2011). Therefore,

we approached these questions by directly quantifying the effect of multiple potential

selection agents across multiple island populations of multiple reptile species within a

single archipelago. Comparing species co-occurring within the same archipelago

allows one to eliminate island-specific factors that vary across different regions such

as latitude, climate, vegetation, primary productivity, etc., but remain relatively

uniform among such co-occurring species (Meiri et al., 2008). This study design

we studied and those that are species-specific.

We assembled a database of unprecedented coverage encompassing body size data for

nearly 10,000 individuals of 16 reptile species (eight lizard and eight snake species),

from 273 islands in the Aegean Sea. These islands vary widely in area, isolation and 
several hypotheses: 1 . Small species increase in size while large species become

smaller as islands decrease in area, increase in isolation (in time and space), and

harbor fewer predators and competitors for the focal species (Heaney, 1978;

Lomolino, 2005); 2. Medium sized species are largest on intermediate-sized islands

and intermediate degrees of isolation, predation and competition (Heaney, 1978); 3.

Interspecific competition affects small species more strongly than large species while

the effect of predation is not size-dependent (Heaney, 1978); 4. Body size patterns on

islands are consistent across taxa (Lomolino, 2005; Köhler et al., 2008).

\section{METHODS}

\section{Study system}

The Aegean Sea has several thousand islands varying across six orders of magnitude

in area. Their geological histories are diverse (Lymberakis \& Poulakakis, 2010) and

the landscapes are a patchwork of dwarf Mediterranean scrub (locally called

2005). Consequently, faunal composition and resource availability vary greatly across

islands. Fifty reptile species inhabit Aegean Sea islands, with the gecko

Mediodactylus kotschyi and the lacertid Podarcis erhardii being most common,

\section{Data collection}

We measured specimens in the field during spring and summer periodically over 33

years (1984-2016). We further measured specimens in eight museum collections

(Zoologische Staatssammlung München, Zoologische Forschungsmuseum Alexander 
Museum, British Natural History Museum, French National Museum of Natural

History, Museum of Comparative Zoology at Harvard University, and Yale Peabody

Museum of Natural History). Finally, we comprehensively surveyed literature and

recorded body size information for as many Aegean island reptiles as possible (data

were extracted from 97 sources; see Appendix 1 for a list). We recorded sex and body

size for 9951 adult individuals of eight lizard and eight snake species originating from

273 islands (Table 1, Appendix 2). We used the most commonly reported size indices:

each species was calculated from data we recorded in the field and from the literature.

To ensure our use of multiple data sources did not bias the results, we compared the

mean body size of specimens measured in museum collections and specimens

measured in the field for several islands. We compared only islands from which we

recorded body size data of at least five males and five females for each data source.

For the two species with sufficient data we found no differences between sources $(P$.

erhardii: field mean $\mathrm{SVL}=61.05 \mathrm{~mm}$, museum $=60.43 \mathrm{~mm}, \mathrm{n}=38$ islands, $\mathrm{t}=1.22$,

$\mathrm{p}=0.23 ;$ M. kotschyi: field $=43.35 \mathrm{~mm}$, museum $=43.68 \mathrm{~mm}, \mathrm{n}=25, \mathrm{t}=-1.05, \mathrm{p}=0.30$ ).

We therefore pooled museum, literature and field data in all further analyzes.

Following most island biogeography studies (studies of body size included; e.g.,

Boback, 2003; Lomolino, 2005; Meiri et al., 2005), we tested the distance from the

nearest mainland as an index of spatial isolation. However, for land-bridge island

systems this index may not adequately quantify effective isolation (Itescu, 2017),

especially in the Aegean Sea archipelago (Foufopoulos \& Ives, 1999). Therefore we

also studied the distance from the closest larger island and a temporal isolation index,

the time since isolation. Distances were calculated using Google Earth tools. Periods 
glacial maximum - "LGM") were calculated by crossing data for the maximum depth

between a focal island and the last landmass to which it was connected with regional-

specific charts of sea-level change since the LGM (see Foufopoulos \& Ives, 1999;

Foufopoulos et al., 2011). Maximum depths were drawn from fine resolution

bathymetric maps of the Hellenic Navy Hydrographic Service

(www.hnhs.gr/geoindex/). Estimations were calculated to a one year resolution, and

we did not round values although we acknowledge and do not presume our method

can accurately estimate isolation time at such a fine resolution. Temporal isolation of

islands isolated earlier than the LGM were assembled from the literature (Appendix

3). We assembled island-specific faunal lists based on the literature and our own field

observations to count the potential predator and competitor species of each focal

population. Predators were defined as all mammals and reptiles likely to prey upon

focal species (Appendix 4). Birds were excluded since their mobility across islands

and their seasonal migration allows them to hunt well away from their breeding sites,

making it impossible to create reliable island-specific lists. To ensure that excluding

birds did not significantly affect our predator richness values we tested the correlation

$0.90(p<0.01)$. We therefore feel confident to exclude bird counts from our database.

We could not quantify potential predatory arthropods (e.g., spiders, scorpions,

centipedes) since reports on either predation on reptiles by arthropods, and island

(for lizards) or other snakes (for snakes), assuming that juveniles of large species 


\section{Analyses}

We examined 16 reptile species for which we had measurements of at least three

allowed us to maximize the number of species and populations as well as the range of

islands and hence, maximize variation in the predictor variables. To avoid size biases

due to sexual size dimorphism, we calculated population mean body size by averaging

male and female means. Only for Ablepharus kitaibelii we used a mean of all

individuals regardless of sex since reliably determining their sex in the field in a non-

invasive manner is extremely difficult.

We first explored for each species whether the relationship of body size with each of

the six island characteristics (island area, distance from the mainland, distance from

the closest larger island, time since isolation, predator richness, and competitor

richness) is linear or curvilinear. To test Heaney's (1978) prediction that the

relationship between size evolution of species and each of the predictor variables is

affected by the species body size we regressed the correlation coefficient of the

relationship between body size (i.e. body length) and each of the six predictor

positive relationship where Heaney's prediction holds, since it asserts small species

would show negative body size-predictor slopes, medium-sized species would have

slopes equal to zero, and large species show positive slopes (see Meiri et al., 2005).

To test Heaney's prediction that interspecific competition is more important for small 
interspecific competition and no trend for predation if the prediction holds. We used

body mass as the predictor variable in these analyses since it is comparable across

taxa, eliminating biases driven by body shape, and therefore is more suitable for inter-

specific comparisons than body length (Feldman \& Meiri, 2013; Feldman et al.,

2016). We then took a meta-analytic approach to explore whether any island

characteristic significantly affects body size across all reptiles we studied in general or

across each suborder (snakes and lizards) separately. We conducted DerSimonian-

Laird random-effect meta-analysis of correlation coefficients (r) of the linear

regressions of body size against each predictor variable in all species as effect sizes,

for each group separately. We used the correlation coefficients from regressions of

$\log 10$-transformed body size (against tested predictors) for all species, to standardize

the $r$ values we analyzed. The meta-analyses were performed using the 'metacor' $\mathrm{R}$

package (Laliberté, 2011). Finally, we examined for each species which of the six

island characteristics comprise the model that best predicts its body size on islands

and compared the selected best models across species. To this end we performed a

multiple regression test for each species, followed by a backward-stepwise model

selection procedure based on $p$-values $(\alpha<0.05)$, using both linear and quadratic terms.

We avoided using the Akaike information criteria for model selection (AIC or AICc

scores) because the models with the lowest scores often had predictors which were

poorly associated with size (i.e. had $p$ values $>0.05$ when significance levels were

estimated), making them non-informative (models with the lowest scores merely

being the best of a collection of poor models; Arnold, 2010; Mac Nally et al., 2017).

Thus, the much maligned p-value approach proved more conservative. Nevertheless,

we present the AICc-based best models for each species in Appendix 5 to highlight 
We avoided over-parameterization by limiting models to include a maximum of three

data points (i.e., islands) per tested predictor. We discarded predictors which were

highly co-linear with others (variance inflation factor $\geq 5$ ) in the same model. To meet

the assumptions of parametric tests we $\log 10$-transformed island area, time since

isolation, and where needed, body size (residual distributions of six of the 16 species

were not normal before transformation; Shapiro-Wilk normality test) in all analyses.

In all cases where we analyzed correlation coefficients (r) as the dependent variable

we used the $r$ values from regressions of $\log 10$-transformed body size (against tested

predictors) for all species to standardize the analyzed values.

\section{RESULTS}

The best models for body size were highly inconsistent across species. Each of the

predictors we tested was correlated with the body size of at least one species, but most

predictor-body size relationships were non-significant, and no predictor was important

for all species (Table 1). We found 15 different models (in terms of variables included and trend signs) across the 16 studied species. Only the snakes Elaphe quatuorlineata

modestus and Natrix natrix) no predictors were significant. Explanatory power and

effect sizes of each predictor varied greatly across the 16 species examined, within

snakes and lizards separately, and even within families (Table 2). In only one out of

16 reptile species (the snake Telescopus fallax) was a quadratic model of body size for

island area significant, and only five species showed a significant linear relationship

(three positive and two negative) between size and area, when area was tested in

univariate models (Fig. 1; see full univariate model statistics in Appendix 6).

Following model selection, T. fallax still showed the same quadratic pattern, and 
significant linear relationships emerged only in lizards (positive in two species and

negative in four). In fact, for lizards island area was the most frequently significant

predictor. For snakes, distance from the mainland was the most frequently significant

predictor, negatively correlated with body size in three species and positively so in

one.

When we regressed the correlation coefficient (r) from the regression of body size

against each predictor variable in each study species against its log body mass, we

found a significant negative relationship for the three isolation indices (distance from

the mainland, distance from the closest larger island and time since isolation). The

results for island area, predator richness and competitor richness in this analysis were

non-significant (Table 3, Fig. 2). Regressing the absolute values of the correlation

coefficients from body length-predator richness and body length-competitor richness

regressions against body mass $(n=16)$ showed that the importance of both predation

(slope $=0.06 \pm 0.07, p=0.40 . R^{2}=0.05$ ) and interspecific competition (slope $=0.08 \pm 0.06$,

$p=0.23 . R^{2}=0.10$ ) for body size variation is not size-dependent (Fig. 3).

The meta-analyses (Table 4) revealed that none of the predictors we tested had a

that). Snake body size, however, significantly increased with island area, as well as

with competitor and predator richness, and declined with the distance from the

mainland and with time since isolation. The only predictor variable that did not

significantly affect snake body size was the distance from the closest larger island

(i.e., the opposite of the lizard pattern). 
Aegean island reptiles show great idiosyncrasy in the way their sizes respond to the

factors we studied. We found great pattern diversity among the species we studied,

with effects of the predictor variables varying in sign, shape (linear, curvilinear) and

significance. None of the predictor variables consistently affected even the majority of

species, and a comparison of the best models across species showed that nearly all

species were affected by a different combination of factors. Very few consistent

patterns emerged, except that most predictors were uninformative for most species (a

consistency of sorts). In line with this finding, the meta-analysis of effect sizes

showed that none of the three isolation indices significantly drives insular body size of

the studied reptiles in a particular direction (i.e., patterns are inconsistent across

species). Island area, predator richness, and competitor richness likely have no general

effect on insular reptile body size. Our results also revealed striking differences in the

response of body size on islands to environmental conditions in lizards and those in

snakes. That said, small reptile species tend to become larger on more isolated islands,

while large species tend to become smaller as geographic and temporal isolation

increases

A common perception in island biogeography is that as islands get smaller and more

isolated, the effects of the insular environment on the traits of their inhabitants

intensify (Melton, 1982; Filin \& Ziv, 2004; Lomolino, 2005). However, when the

effects of area and isolation on reptile body size are directly tested, results are often

inconsistent. For snakes, Hasegawa \& Moriguchi (1989) found a negative correlation

between body size and island area, Boback's (2003) meta-analysis revealed no

correlation between them, and Meik et al. $(2010,2012)$ found a strong positive

correlation in speckled rattlesnakes (Crotalus mitchellii). Our meta-analysis results for 
species we studied (seven out of the eight species) island area is not a particularly

important predictor of body size according to model selection (for Telescopus fallax it

is, but the relationship with body size is hump-shaped). Boback (2003) and Meik et al.

(2010) found no association between size and either temporal or geographic isolation

whereas we found a negative relationship. The frequent inclusion of island area in the best models of lizards (for seven out of eight species) is somewhat surprising considering results of previous studies (Soulè, 1966; Dunham et al., 1978; Losos et

al., 2004; Meiri, 2007, but see Donihue et al., 2016). However, the fact that the

direction of the relationship changes across species points to no general trend.

We cannot support most of Heaney's (1978) predictions in the case of reptiles. It is

clear that none of the island characteristics we examined drives reptile body size

patterns in the predicted way. Moreover, isolation, regardless of the index tested,

shows the opposite patterns. These results highlight a role of island isolation in

driving reptile body size evolution (Van Valen, 1973; Lomolino, 2005). Island area,

however, in contrast to theory (Heaney, 1978; Lomolino, 2005), has no overall effect

on patterns of reptile body size variation on islands, at least in the Aegean Sea

archipelago. Our results also refute Heaney's (1978) prediction that interspecific

competition influences small species more strongly than large species, but supports

his prediction that the importance of predation for size variation on island is not size-

biased.

Surprisingly, we only found few, weak effects of biotic interactions. As others have

used island area and isolation as proxies for biotic effects and found significant

associations with body size (Lomolino, 2005), we expected that testing the effect of

the biotic interactions directly would result in stronger patterns. This, however, 
study species (less than a quarter of the species had these factors included in their best

model). For snakes, but not for lizards or for reptiles in general (i.e., as a group), the

meta-analysis showed a tendency towards larger sizes where predator and competitor

richness is greater. We think the weak effect of competitor and predator richness

implies that maybe many, possibly inefficient, competitors and predators do not

necessarily impose a stronger selection pressure than one or two dominant

competitors $\backslash$ predators. Therefore, we suspect that despite its common use as a

predation pressure index in the literature (e.g., Pérez-Mellado et al., 1997; Cooper et

al., 2004), predator richness poorly reflects predation intensity (Meiri et al., 2005;

Itescu et al., 2017). Similarly, competitor richness may be a weak index of

competition intensity (Meiri et al., 2014). Another possibility is that significant

evolutionary changes are apparent only on predator-free, rather than predator-poor,

islands.

Two important factors that we did not test in this study but are often thought to shape

(Case, 1978; Melton, 1982). For example, gigantism on islands has been explained by

the need to evolve a large size under conditions of stronger intra-specific competition,

where predation pressure is low (Pafilis et al., 2009). Territoriality, which involves

defending resources against conspecifics and characterizes some of our study species,

is also thought to be associated with larger sizes on islands (Case, 1978; Keehn et al., 
Furthermore, resource limitation may drive cannibalism in insular reptiles,

consequently selecting for larger body sizes (Pafilis et al., 2009).

While body size variation on islands is commonly examined under a framework of

adaptations, one cannot rule out alternative possibilities such as habitat-driven plastic

phenotypic responses (in contrast to adaptive genetic response) or founder effects.

These possibilities seem especially relevant in our study system, considering the

minor effect commonly suggested selection agents have on reptile body size patterns.

For example, individual growth rates can vary as a result of genetic changes (i.e.,

adaptation) or plastic changes (e.g., more food permits faster growth). There are

indications that plastic growth rate variability across insular populations resulting

from variation in resource availability may produce non-adaptive body size

differences (Case, 1976; Forsman, 1991; Madsen \& Shine, 1993). Additionally, where

predators are rare, foraging and basking times may increase, thereby allowing

enhanced growth. Of course, direct selection on growth rates rather than on body size

per se (e.g., due to ontogenetic differences in food limitation, competition intensity or

size-biased predation pressure) may also drive population-level body size variation

(Aubret, 2012). Vincent et al. (2009) proposed that body size variation in snakes is no

more than an evolutionary spandrel, with gape size being the true trait under selection.

Another alternative non-adaptive explanation for body size variation across

populations is that where adult mortality rates are low (e.g., where predation is low)

larger adult sizes are attained because individuals survive longer and reptiles grow 
adaptive, and novel approaches (Diniz-Filho \& Raia, 2017) may allow better

discrimination between adaptive and non-adaptive patterns in the near future.

An interesting and important pattern that emerged from our results is that lizards and

snakes, at the sub-order level, differ markedly in how their sizes respond to the factors

we studied. In fact, we found they show an exactly opposite picture to each other.

Lizard body size shows no general response to island conditions, except for a weak

tendency to decline with distance from the closest larger island. In contrast, snake

body size responds to most factors apart from distance from the closest larger island.

It tends to increase with island area, competitor richness and predator richness, and to

decline with distance from the mainland and with time since isolation. Generally, the

patterns found for snakes follow the common predictions regarding insular evolution

in large species (Heaney, 1978). Interestingly, however, those of lizards do not follow

the patterns predicted for small species (Heaney, 1978), in the most part. The patterns

we found for each of the two groups separately, suggest that the overall effect of

isolation on reptile body size is somewhat complex. Likely, the negative trend in the

cases of the distance from the mainland and time since isolation are driven by the

tendency of snakes (i.e., generally larger species) towards dwarfism as these factors

increase. In contrast, the negative trend for the distance from the closest larger island

is probably driven by the tendency of lizards (i.e., generally smaller species) to grow

larger on more remote islands. At this point we cannot discern the reasons different

isolation indices affect one group more strongly than the other. However, we

speculate that either the effect of isolation reflects another factor or combination of 
strong founder effect signals or is non-adaptive. Inconsistent patterns of lizard and

snake body size evolution on islands have been shown before (e.g., the island rule, cf.

Boback \& Guyer, 2003 for snakes and Meiri, 2007 for lizards).

Conducting a comparative study of such a wide scope as this one will always create

logistic and methodological challenges and several caveats should be noted. The role

of shared ancestral condition in shaping body size variation on islands needs to be

addressed by comparing phylogenetic and non-phylogenetic models. However, the

population-level phylogenies currently available for the studied species did not allow

us to robustly examine this aspect. Therefore, we highlight the importance of island-

level molecular studies, which will generally facilitate further investigation of

evolutionary patterns. The nature of some of our predictors (e.g., competitor richness,

predator richness) necessitates some general assumptions (e.g., that a predator species

preys upon its prey species wherever they co-exist, and that we can correctly identify

all important competitors and predators). Since we consistently kept these

assumptions regarding all species and islands, we are confident they have not biased

our results. Perhaps the most important drawback, and most challenging to face, is

small sample sizes. With almost 10,000 adult reptiles examined we still came quite

short in samples for some populations and for certain species. Several species (e.g.,

Macrovipera schweizeri, Blanus strauchi, Podarcis levendis) simply occur on too few

islands to be properly analyzed. For the rest, an inherent trade-off exists between the

numbers of sampled islands and sampled individuals per island. Our main unit of 
acknowledge the possibility that low statistical power may have affected our results in

some cases. Yet, the general patterns and inconsistencies we found across species are

apparent even across the few best-sampled species, thus we have confidence our

conclusions are valid. Moreover, the number of species we examined and the number

of insular populations we sampled within each of these species are both of

unprecedented scope, at least for reptiles. We think this enables us to robustly draw

valid conclusions from our results.

Our results provide a compelling example for the statistical issue of which model-

think that, if anything, $p=0.05$ is not conservative enough (e.g., Johnson, 2013; would have made us infer that many variables, that have the most tenuous relationship 
The results of this study indicate that to a large extent different species respond

idiosyncratically to the insular environment. Thus, reptile body size variation seems to

be affected more by species identity than by island conditions, at least in this study

system. This contradicts the theory asserting that evolutionary patterns of body size on

islands are general across different taxa. The fact that none of the predictors we tested

consistently affected a majority of the species, and that the best models differed

greatly across species, highlights the importance of testing several potential driving

mechanisms simultaneously, as we did, to prevent unjustified generalizations from

being reached. We thus conclude that body size evolution on island is probably

species- and island-specific, and generalizations over-simplify the complex patterns

and processes of size evolution. This study elucidates the need for a major re-thinking

of the insular evolution paradigm, away from island characteristics as monotonous

predictors of animal trait evolution, and into the need to quantify relevant ecological

effects for different study systems.

\section{ACKNOWLEDGMENTS}

We thank Aviv Bejerano, Stav Brown, Nir Einav, Tamar Freud, Alison Gainsbury,

Efrat Golan, Eden Goshen, Anat Hartmann, Simon Jamison, Lama Khoury,

Menachem Kurzits, Shani Levinkind, Amir Lewin, Erez Maza, Michael Mosses, Gaya

Savion, Eylon Sharoni, Achiad Sviri, Oliver Tallowin, Karin Tamar, Alexandros

Vezyrakis and Keren-Or Werheimer for all their help with field work. We deeply

appreciate the assistance of Michael Franzen, and Frank Glaw (Zoologische

Staatssammlung München), Dennis Rödder, Ursula Butt, and Wolfgang Böhme 
Diniz-Filho, and two anonymous reviewers for providing insightful and constructive

reviews, that greatly contributed to improve earlier versions of this paper. All work

was conducted with permission from the Greek Ministry of Environment, Energy, and

Climate Change (Permit 20305/824). The study was funded by an Israel Science

Foundation (ISF) grant \#1005/12. The authors have no conflict of interests to declare.

SUPPORTING INFORMATION

Appendix 1. Reference list for literature containing body size data.

Appendix 2. Data used for analyses.

Appendix 3. Literature sources for isolation time of islands isolated before LGM.

Appendix 4. A list of potential predator species included in our analyses.

Appendix 5. Best models for each species based on AICc scores.

\section{DATA ACCESSIBILITY}

All the data analyzed in this study is available in Appendix 2.

\section{BIOSKETCH}

Yuval Itescu is a PhD candidate interested in the biogeographic patterns and the

processes driving the evolution of morphological and life history trait variation of

animals in general and insular animals specifically. He is also fascinated by the 
Adler, G.H. \& Levins, R. (1994) The island syndrome in rodent populations. The

Quarterly Review of Biology, 69, 473-490.

Anderson, R.P. \& Handley, C.O. (2002) Dwarfism in insular sloths: biogeography,

Arnold, E.N. (1979) Indian Ocean giant tortoises: their systematics and island

adaptations. Philosophical Transactions of the Royal Society B: Biological Sciences,

286, $127-145$.

Arnold, T.W. (2010) Uninformative parameters and model selection using Akaike's

Information Criterion. Journal of Wildlife Management, 74, 1175-1178.

Aubret, F. (2012) Body-size evolution on islands: are adult size variations in tiger

snakes a nonadaptive consequence of selection on birth size? The American

Naturalist, 179, 756-767.

Aubret, F. (2015) Island colonisation and the evolutionary rates of body size in insular

neonate snakes. Heredity, 115, 349-356.

Benjamin, D.J., Berger, J.O., Johannesson, M., Nosek, B.A., Wagenmakers, E.-J.,

Berk, R., Bollen, K.A., Brembs, B., Brown, L., Camerer, C., Cesarini, D., Chambers,

C.D., Clyde, M., Cook, T.D., De Boeck, P., Dienes, Z., Dreber, A., Easwaran, K.,

Efferson, C., Fehr, E., Fidler, F., Field, A.P., Forster, M., George, E.I., Gonzalez, R.,

Goodman, S., Green, E., Green, D.P., Greenwald, A., Hadfield, J.D., Hedges, L.V.,

Held, L., Ho, T.H., Hoijtink, H., Hruschka, D.J., Imai, K., Imbens, G., Ioannidis, 
Nakagawa, S., Nyhan, B., Parker, T.H., Pericchi, L., Perugini, M., Rouder, J.,

Rousseau, J., Savalei, V., Schönbrodt, F.D., Sellke, T., Sinclair, B., Tingley, D., Van

Zandt, T., Vazire, S., Watts, D.J., Winship, C., Wolpert, R.L., Xie, Y., Young, C.,

576

Zinman, J. \& Johnson, V.E. (2017) Redefine statistical significance. Nature Human

577

Behaviour, DOI:10.1038/s41562-017-0189-z.

578

Boback, S.M. (2003) Body size evolution in snakes: evidence from island

populations. Copeia, 2003, 81-94.

Boback, S.M. \& Guyer, C. (2003) Empirical evidence for an optimal body size in

snakes. Evolution, 57, 345-451.

Calsbeek, R. \& Cox, R.M. (2010) Experimentally assessing the relative importance of

Calsbeek, R. \& Cox, R.M. (2011) Calsbeek \& Cox reply. Nature, 475, E3-E3.

Case, T.J. (1976) Body size differences between populations of the chuckwalla,

Sauromalus obesus. Ecology, 57, 313-323.

Case, T.J. (1978) A general explanation for insular body size trends in terrestrial

Case, T.J. \& Schwaner, T.D. (1993) Island/mainland body size differences in 
Darlington, P.J. (1957) Zoogeography: the geographical distribution of animals. John

Wiley \& Sons, New York.

Diniz-Filho, J.A.F. \& Raia, P. (2017) Island Rule, quantitative genetics and brain-

body size evolution in Homo floresiensis. Proceedings of the Royal Society B:

Biological Sciences, 284, 20171065.

Donihue, C.M., Brock, K.M., Foufopoulos, J. \& Herrel, A. (2016) Feed or fight:

testing the impact of food availability and intraspecific aggression on the functional

ecology of an island lizard. Functional Ecology, 30, 566-575.

602

Dunham, A.E., Tinkle, D.W. \& Gibbons, J.W. (1978) Body Size in Island Lizards: A

Cautionary Tale. Ecology, 59, 1230-1238.

Faurby, S. \& Svenning, J.-C. (2016) Resurrection of the Island Rule: Human-Driven 
Filin, I. \& Ziv, Y. (2004) New theory of insular evolution: unifying the loss of

dispersability and body-mass change. Evolutionary Ecology Research, 6, 115-124.

Forsman, A. (1991) Variation in sexual size dimorphism and maximum body size

Foufopoulos, J. \& Ives, A.R. (1999) Reptile extinctions on land-bridge islands: lifehistory attributes and vulnerability to extinction. The American Naturalist, 153, 1-25.

Foufopoulos, J., Kilpatrick, A.M. \& Ives, A.R. (2011) Climate change and elevated

Glaw, F., Köhler, J., Townsend, T.M. \& Vences, M. (2012) Rivaling the world's

Hasegawa, M. (2003) Ecological diversification of insular terrestrial reptiles: a review

Research, 7, 59-68.

Hasegawa, M. \& Mori, A. (2008) Does a gigantic insular snake grow faster or live

longer to be gigantic? Evidence from a long-term field study. South American Journal 
Asia (ed. by M. Matui, T. Hikida and R.C. Goris), pp. 414-432. The Herpetological

Society of Japan.

Heaney, L.R. (1978) Island area and body size of insular mammals: evidence from the

tri-colored squirrel (Callosciurus prevosti) of Southeast Asia. Evolution, 32, 29-44.

Heaney, L.R. (2000) Dynamic disequilibrium: a long-term, large-scale perspective on

the equilibrium model of island biogeography. Global Ecology and Biogeography, 9,

Hedges, S.B. (2008) At the lower size limit in snakes: two new species of

Hedges, S.B. \& Thomas, R. (2001) At the lower size limit in amniote vertebrates: a

Itescu, Y. (2017) Evolution on islands: testing the extent and consistency of the effects 
Itescu, Y., Schwarz, R., Moses, M., Pafilis, P. \& Meiri, S. (2016) Record sizes for the 655

Turkish house gecko, Hemidactylus turcicus, from Aegean islands, Greece. The

Herpetological Bulletin, 138, 24-26.

Johnson, V.E. (2013) Revised standards for statistical evidence. Proceedings of the

National Academy of Sciences, 110, 19313-19317.

Keehn, J.E., Nieto, N.C., Tracy, C.R., Gienger, C.M. \& Feldman, C.R. (2013)

Evolution on a desert island: body size divergence between the reptiles of Nevada's

Anaho Island and the mainland around Pyramid Lake. Journal of Zoology, 291, 269-

King, R.B. (1989) Body size variation among island and mainland snake populations.

Herpetologica, 45, 84-88.

Köhler, M., Moyà-Solà, S. \& Wrangham, R.W. (2008) Island rules cannot be broken.

Science, 335, 1086-1089.

Laliberté, E. (2011) Metacor: Meta-analysis of correlation coefficients. R package.

$\underline{\text { http://CRAN.R-project.org/package=metacor }}$

Leisler, B. \& Winkler, H. (2015) Evolution of island warblers: beyond bills and 
Lomolino, M.V. (2005) Body size evolution in insular vertebrates: generality of the

island rule. Journal of Biogeography, 32, 1683-1699.

Losos, J.B. \& Pringle, R.M. (2011) Competition, predation and natural selection in

Losos, J.B., Schoener, T.W. \& Spiller, D.A. (2004) Predator-induced behaviour shifts

Lymberakis, P. \& Poulakakis, N. (2010) Three continents claiming an archipelago: 
speckled rattlesnakes from the western Sea of Cortés, Mexico. Herpetological Review,

43, 556-560.

Meiri, S. (2007) Size evolution in island lizards. Global Ecology and Biogeography,

16, $702-708$.

Meiri, S. (2008) Evolution and ecology of lizard body sizes. Global Ecology and

Biogeography, 17, 724-734.

Meiri, S., Dayan, T. \& Simberloff, D. (2005) Area, isolation and body size evolution

in insular carnivores. Ecology Letters, 8, 1211-1217.

Meiri, S., Kadison, A.E., Novosolov, M., Pafilis, P., Foufopoulos, J., Itescu, Y., Raia,

P. \& Pincheira-Donoso, D. (2014) The number of competitor species is unlinked to

sexual dimorphism. Journal of Animal Ecology, 83, 1302-1312.

Meiri, S., Meijaard, E., Wich, S.A., Groves, C.P. \& Helgen, K.M. (2008) Mammals of

Borneo-small size on a large island. Journal of Biogeography, 35, 1087-1094.

Melton, R.H. (1982) Body size and island Peromyscus: a pattern and a hypothesis.

Evolutionary theory, 6, 113-126.

Pafilis, P., Meiri, S., Foufopoulos, J. \& Valakos, E. (2009) Intraspecific competition

and high food availability are associated with insular gigantism in a lizard.

Naturwissenschaften, 96, 1107-1113. 
Pérez-Mellado, V., Corti, C. \& Lo Cascioa, P. (1997) Tail autotomy and extinction in

Mediterranean lizards. A preliminary study of continental and insular populations.

Journal of Zoology, 243, 533-541.

Schoener, T.W. (1970) Size patterns in West Indian Anolis lizards. II. Correlations

Schwaner, T.D. (1985) Population structure of black tiger snakes, Notechis ater niger,

on offshore islands of South Australia. Biology of Australasian frogs and reptiles (ed.

Shine, R. (1987) Ecological comparisons of island and mainland populations of

Australian tigersnakes (Notechis: Elapidae). Herpetologica, 43, 233-240.

Soulé, M. (1966) Trends in the insular radiation of a lizard. The American Naturalist,

100, 47-64.

Valakos, E.D., Pafilis, P., Sotiropoulos, K., Lymberakis, P., Maragou, P. \&

Foufopoulos, J. (2008) The amphibians and reptiles of Greece. Edition Chimaira,

Van Valen, L. (1973) Pattern and the balance of nature. Evolutionary theory, 1, 31-49.

Vervust, B., Grbac, I. \& Van Damme, R. (2007) Differences in morphology, 
(2009) Insular gigantism and dwarfism in a snake, adaptive response or spandrel to

selection on gape size. Nature Precedings,

http://precedings.nature.com/documents/3360/version/1.

Appendix 1 - Reference list for literature containing body size data

Appendix 3 - Literature sources for isolation time of islands isolated before the LGM. 
Table 1. Summary of data and the effects of each predictor on each species. $(+)$ marks a positive correlation; $(-)$ a negative correlation; ( U ) a

positive quadratic relationship; $(\cap)$ a negative quadratic relationship; (NS) non-significant correlation; Full statistics of all models (with sample

sizes) are given in Table 2. Population mean size range refers to SVL in lizards and total length in snakes.

\begin{tabular}{|c|c|c|c|c|c|c|c|c|c|c|c|c|}
\hline Group & Family & Species & Islands & Individuals & $\begin{array}{l}\text { Population mean } \\
\text { size range }(\mathrm{mm})\end{array}$ & $\begin{array}{c}\text { Species } \\
\text { mean body } \\
\text { mass (g) }\end{array}$ & Area & $\begin{array}{l}\text { Distance } \\
\text { from the } \\
\text { mainland }\end{array}$ & $\begin{array}{l}\text { Distance from closest } \\
\text { larger island }\end{array}$ & $\begin{array}{l}\text { Time since } \\
\text { isolation }\end{array}$ & Predators & Competitors \\
\hline \multirow{8}{*}{ Lizards } & \multirow{2}{*}{ Gekkonidae } & Hemidactylus turcicus & 27 & 270 & $42.04-59.89$ & 3.3 & + & NS & NS & NS & NS & NS \\
\hline & & Mediodactylus kotschyi & 86 & 2071 & $33.52-49.88$ & 2.8 & - & NS & NS & NS & NS & $\cap$ \\
\hline & \multirow{5}{*}{ Lacertidae } & Podarcis erhardii & 118 & 5323 & $52.87-75.23$ & 6.0 & - & - & + & NS & NS & NS \\
\hline & & Podarcis gaigeae & 14 & 641 & $57.37-77.67$ & 8.4 & NS & - & + & - & NS & NS \\
\hline & & Podarcis milensis & 8 & 116 & $53.65-67.09$ & 4.1 & - & NS & NS & + & NS & NS \\
\hline & & Lacerta trilineata & 16 & 231 & $107.33-141.85$ & 69.9 & - & + & NS & NS & NS & NS \\
\hline & & Ophisops elegans & 14 & 143 & $40.10-48.53$ & 2.0 & + & NS & NS & NS & - & NS \\
\hline & Scincidae & Ablepharus kitaibelii & 24 & 180 & $35.66-44.84$ & 1.4 & NS & + & NS & NS & NS & NS \\
\hline \multirow{8}{*}{ Snakes } & Boidae & Eryx jaculus & 8 & 48 & $269.79-516.33$ & 52.5 & NS & - & NS & NS & - & NS \\
\hline & \multirow{5}{*}{ Colubridae } & Dolichophis caspius & 11 & 72 & $1085.40-1886.00$ & 625.2 & NS & NS & NS & NS & - & + \\
\hline & & Eirenis modestus & 8 & 33 & $386.00-543.00$ & 19.8 & NS & NS & NS & NS & NS & NS \\
\hline & & Elaphe quatuorlineata & 11 & 70 & $1036.20-1525.61$ & 846.9 & NS & - & NS & NS & NS & NS \\
\hline & & Natrix natrix & 11 & 55 & $566.25-910.00$ & 91.6 & NS & NS & NS & NS & NS & NS \\
\hline & & Telescopus fallax & 12 & 56 & $477.43-903.33$ & 44.9 & $\cap$ & NS & NS & NS & NS & NS \\
\hline & \multirow{2}{*}{ Viperidae } & Vipera ammodytes & 15 & 152 & $281.33-592.25$ & 28.1 & NS & - & NS & NS & NS & NS \\
\hline & & Vipera xanthina & 8 & 51 & $490.78-1493.33$ & 276.0 & NS & NS & NS & $\mathrm{U}$ & NS & NS \\
\hline
\end{tabular}


Table 2. Best models by species. $\mathrm{n}$ is island sample size. Body size was $\log 10$ -

\begin{tabular}{|c|c|c|c|c|c|c|c|c|c|c|}
\hline Group & Family & Species & $\mathbf{n}$ & Predictor & Slope & SE & Intercept & SE & $\mathbf{P}$ & $\begin{array}{c}\text { Adjusted } \\
\mathbf{R}^{2}\end{array}$ \\
\hline \multirow{8}{*}{ Lizards } & & Hemidactylus & 27 & $\log$ area & 1.91 & 0.59 & 46.37 & 1.01 & $<0.01$ & 0.26 \\
\hline & Gekkonidae & $\begin{array}{l}\text { Mediodactylus } \\
\text { kotschyi }\end{array}$ & 86 & $\begin{array}{l}\text { log area } \\
\text { competitor richness } \\
\text { competitor richness }\left({ }^{\wedge} 2\right)\end{array}$ & $\begin{array}{l}-0.86 \\
2.81 \\
-0.38\end{array}$ & $\begin{array}{l}0.44 \\
0.81 \\
0.12\end{array}$ & 39.64 & 0.88 & $\begin{array}{l}0.05 \\
<0.01 \\
<0.01\end{array}$ & 0.10 \\
\hline & \multirow{5}{*}{ Lacertidae } & $\begin{array}{l}\text { Podarcis } \\
\text { erhardii* }\end{array}$ & 118 & $\begin{array}{l}\text { log area } \\
\text { distance from the mainland } \\
\text { log distance from closest larger landmass }\end{array}$ & $\begin{array}{l}(-)<0.01 \\
(-)<0.01 \\
0.01\end{array}$ & $\begin{array}{l}<0.01 \\
<0.01 \\
<0.01\end{array}$ & 1.80 & $<0.01$ & $\begin{array}{l}0.02 \\
0.01 \\
0.04\end{array}$ & 0.07 \\
\hline & & $\begin{array}{l}\text { Podarcis } \\
\text { gaigeae* }^{*}\end{array}$ & 14 & $\begin{array}{l}\text { distance from the mainland } \\
\text { log distance from closest larger landmass } \\
\text { log time since isolation }\end{array}$ & $\begin{array}{l}(-)<0.01 \\
0.07 \\
-0.08\end{array}$ & $\begin{array}{l}<0.01 \\
0.02 \\
0.02\end{array}$ & 2.53 & 0.19 & $\begin{array}{l}<0.01 \\
0.01 \\
<0.01\end{array}$ & 0.51 \\
\hline & & $\begin{array}{l}\text { Podarcis } \\
\text { milensis }\end{array}$ & 8 & $\begin{array}{l}\log \text { area } \\
\text { log time since isolation }\end{array}$ & $\begin{array}{l}-2.23 \\
2.06\end{array}$ & $\begin{array}{l}0.74 \\
0.68\end{array}$ & 48.63 & 3.80 & $\begin{array}{l}0.03 \\
0.03\end{array}$ & 0.75 \\
\hline & & $\begin{array}{l}\text { Lacerta } \\
\text { trilineata }\end{array}$ & 16 & $\begin{array}{l}\text { log area } \\
\text { distance from the mainland }\end{array}$ & $\begin{array}{l}-7.28 \\
0.14\end{array}$ & $\begin{array}{l}3.01 \\
0.05\end{array}$ & 136.02 & 7.45 & $\begin{array}{l}0.03 \\
0.01\end{array}$ & 0.43 \\
\hline & & $\begin{array}{l}\text { Ophisops } \\
\text { elegans }\end{array}$ & 14 & $\begin{array}{l}\text { log area } \\
\text { predator richness }\end{array}$ & $\begin{array}{l}3.06 \\
-0.67\end{array}$ & $\begin{array}{l}1.00 \\
0.28\end{array}$ & 41.61 & 1.28 & $\begin{array}{l}0.01 \\
0.04\end{array}$ & 0.36 \\
\hline & Scincidae & Ablepharus & 24 & distance from the mainland & 0.03 & 0.01 & 39.13 & 0.73 & $<0.01$ & 0.30 \\
\hline \multirow{7}{*}{ Snakes } & Boid: & Eryx jaculus & 8 & $\begin{array}{l}\text { distance from the mainland } \\
\text { predator richness }\end{array}$ & $\begin{array}{l}-5.77 \\
-26.20\end{array}$ & $\begin{array}{l}0.55 \\
3.56\end{array}$ & 1302.57 & 89.63 & $\begin{array}{l}<0.01 \\
<0.01\end{array}$ & 0.94 \\
\hline & \multirow{5}{*}{ Colubridae } & $\begin{array}{l}\text { Dolichophis } \\
\text { caspius }\end{array}$ & 11 & $\begin{array}{l}\text { predator richness } \\
\text { competitor richness }\end{array}$ & $\begin{array}{l}-326.08 \\
447.95\end{array}$ & $\begin{array}{l}88.43 \\
116.38\end{array}$ & 2751.25 & 391.42 & $\begin{array}{l}0.01 \\
<0.01\end{array}$ & 0.58 \\
\hline & & $\begin{array}{l}\text { Eirenis } \\
\text { modestus }\end{array}$ & 8 & none & - & - & - & - & - & - \\
\hline & & $\begin{array}{l}\text { Elaphe } \\
\text { quatuorlineata }\end{array}$ & 11 & distance from the mainland & -2.79 & 0.48 & 1482.29 & 37.59 & $<0.01$ & 0.77 \\
\hline & & Natrix natrix* & 11 & none & - & - & - & - & - & - \\
\hline & & $\begin{array}{l}\text { Telescopus } \\
\text { fallax* }\end{array}$ & 12 & $\begin{array}{l}\log \text { area } \\
(\log \text { area })^{\wedge} 2\end{array}$ & $\begin{array}{l}0.55 \\
-0.09\end{array}$ & $\begin{array}{l}0.21 \\
0.04\end{array}$ & 2.04 & 0.26 & $\begin{array}{l}0.03 \\
0.04\end{array}$ & 0.43 \\
\hline & Viperidae & Vipera & 15 & distance from the mainland & $(-)<0.01$ & $<0.01$ & 2.74 & 0.04 & $<0.01$ & 0.63 \\
\hline
\end{tabular}




\begin{tabular}{|c|c|c|c|c|c|c|c|c|c|c|}
\hline Group & Family & Species & $\mathrm{n}$ & Predictor & Slope & SE & Intercept & SE & $\mathbf{P}$ & $\begin{array}{c}\text { Adjusted } \\
\mathbf{R}^{2}\end{array}$ \\
\hline & & ammodytes & & & & & & & & \\
\hline & & $\begin{array}{l}\text { Vipera } \\
\text { xanthina* }\end{array}$ & 8 & $\begin{array}{l}\text { log time since isolation } \\
(\log \text { time since isolation })^{\wedge} 2\end{array}$ & $\begin{array}{l}-6.94 \\
0.71\end{array}$ & $\begin{array}{l}1.86 \\
0.19\end{array}$ & 19.42 & 4.39 & $\begin{array}{l}0.01 \\
0.01\end{array}$ & 0.65 \\
\hline
\end{tabular}

753 
Table 3. Results of the regression of the correlation coefficient (r) between body size

(g). Significant results are highlighted in bold.

\begin{tabular}{|l|l|l|l|l|l|l|}
\hline Predictors & Slope & SE & Intercept & SE & P & $\mathbf{R}^{2}$ \\
\hline Log area & 0.14 & 0.13 & -0.11 & 0.21 & 0.32 & 0.07 \\
\hline Distance from the mainland & $\mathbf{- 0 . 3 0}$ & $\mathbf{0 . 1 2}$ & $\mathbf{0 . 2 2}$ & $\mathbf{0 . 2 0}$ & $\mathbf{0 . 0 3}$ & $\mathbf{0 . 2 9}$ \\
\hline Log Distance from closest larger island & $\mathbf{- 0 . 2 0}$ & $\mathbf{0 . 0 8}$ & $\mathbf{0 . 3 3}$ & $\mathbf{0 . 1 3}$ & $\mathbf{0 . 0 3}$ & $\mathbf{0 . 3 0}$ \\
\hline Log Time since isolation & $\mathbf{- 0 . 3 0}$ & $\mathbf{0 . 0 9}$ & $\mathbf{0 . 3 6}$ & $\mathbf{0 . 1 5}$ & $\mathbf{0 . 0 1}$ & $\mathbf{0 . 4 2}$ \\
\hline Predator richness & 0.20 & 0.11 & -0.18 & 0.19 & 0.11 & 0.17 \\
\hline Competitor richness & 0.13 & 0.11 & -0.04 & 0.18 & 0.27 & 0.08 \\
\hline
\end{tabular}

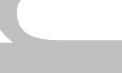

(1)
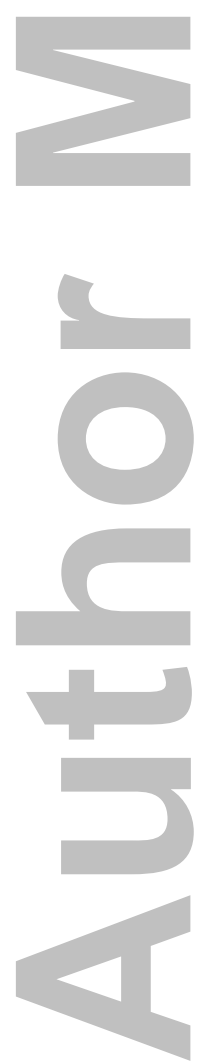
Table 4. Meta-analysis results for all reptiles, only lizards and only snakes. $\mathrm{P}$ values are for $\mathrm{H}_{0}: \mathrm{r}=0$. Significant results are highlighted in bold.

\begin{tabular}{|c|c|c|c|c|c|c|c|c|c|}
\hline \multirow{2}{*}{ Predictors } & \multicolumn{3}{|c|}{ All reptiles } & \multicolumn{3}{|c|}{ Lizards } & \multicolumn{3}{|c|}{ Snakes } \\
\hline & Mean r & Range (r) & $\mathbf{P}$ & Mean $\mathbf{r}$ & Range (r) & $\mathbf{P}$ & Mean $\mathbf{r}$ & Range (r) & $\mathbf{P}$ \\
\hline Log area $\left(\mathrm{km}^{2}\right)$ & 0.108 & $-0.106-0.313$ & 0.16 & -0.082 & $-0.326-0.173$ & 0.27 & 0.410 & $0.146-0.620$ & $<0.01$ \\
\hline Distance from the & -0.201 & $-0.433-0.055$ & 0.06 & 0.130 & $-0.129-0.372$ & 0.16 & -0.581 & $-0.777--0.281$ & $<0.01$ \\
\hline $\begin{array}{l}\text { Log distance from closest } \\
\text { larger island }(\mathrm{km})\end{array}$ & 0.068 & $-0.070-0.204$ & 0.17 & 0.152 & $-0.028-0.323$ & 0.05 & -0.124 & $-0.361-0.128$ & 0.17 \\
\hline $\begin{array}{l}\text { Log time since isolation } \\
\text { (years) }\end{array}$ & -0.042 & $-0.224-0.142$ & 0.33 & 0.077 & $-0.134-0.282$ & 0.24 & -0.263 & $-0.536-0.058$ & 0.05 \\
\hline Predator richness & 0.096 & $-0.098-0.284$ & 0.16 & -0.088 & $-0.278-0.108$ & 0.19 & 0.443 & $0.182-0.645$ & $<0.01$ \\
\hline Competitor richness & 0.147 & $-0.035-0.320$ & 0.06 & 0.003 & $-0.190-0.196$ & 0.49 & 0.423 & $0.179-0.618$ & $<0.01$ \\
\hline
\end{tabular}


Figure 1. Body size as a function of island area: $\mathbf{a}-$ Mediodactylus kotschyi; $\mathbf{b}-$

Hemidactylus turcicus; $\mathbf{c}$-Podarcis erhardii; $\mathbf{d}$-Podarcis gaigeae; $\mathbf{e}$-Podarcis

milensis; $\mathbf{f}$ - Ophisops elegans; $\mathbf{g}$ - Lacerta trilineata $; \mathbf{h}$ - Ablepharus kitaibelii; $\mathbf{i}$ -

Dolichophis caspius; $\mathbf{j}$-Eryx jaculus; $\mathbf{k}$-Eirenis modestus; $\mathbf{l}$-Elaphe

quatuorlineata; $\mathbf{m}$ - Natrix natrix; $\mathbf{n}$ - Telescopus fallax; $\mathbf{0}$-Vipera ammodytes; $\mathbf{p}$ -

Vipera xanthina. Body size index is: SVL for species a, b, e, $\mathrm{f}, \mathrm{g}, \mathrm{h}$; $\log \mathrm{SVL}$ for

species c, d; Total length for species i, j, k, l; Log total length for species m, n, o, p.

Full trend lines indicate a significant relationship $(\mathrm{p}<0.05)$.

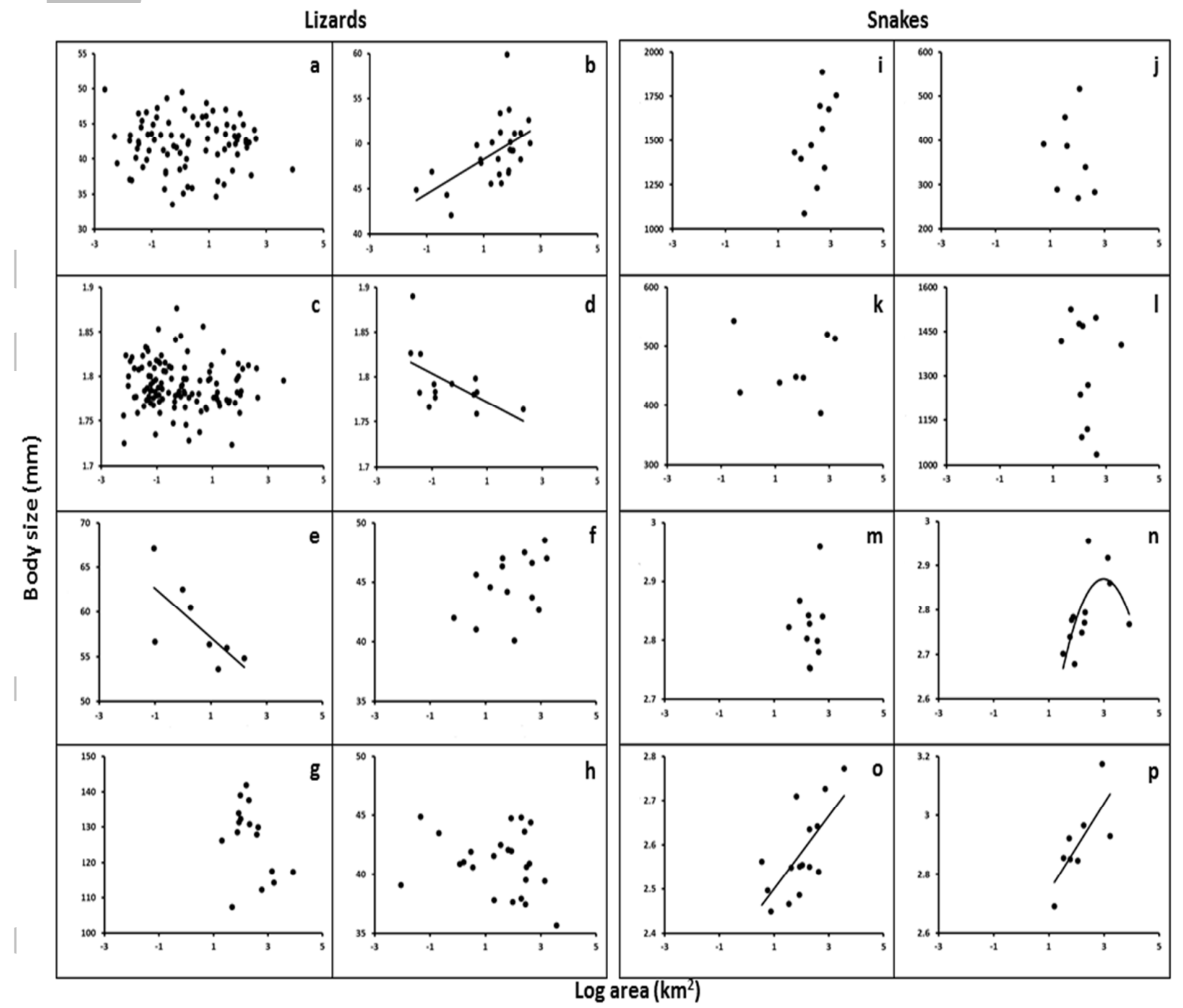


Figure 2. The relationship between the correlation coefficient (r) of body length (mm;

SVL for lizards, total length for snakes, see text) against each predictor variable and

the $\log$ mean body mass (g) of each species. Panels show: $\mathbf{a}-\log$ island area $\left(\mathrm{km}^{2}\right) ; \mathbf{b}$

774

- distance from the mainland $(\mathrm{km}) ; \mathbf{c}-\log$ distance from the closest larger island

$(\mathrm{km}) ; \mathbf{d}$ - log time since isolation (years); $\mathbf{e}$ - predator richness; $\mathbf{f}$ - competitor

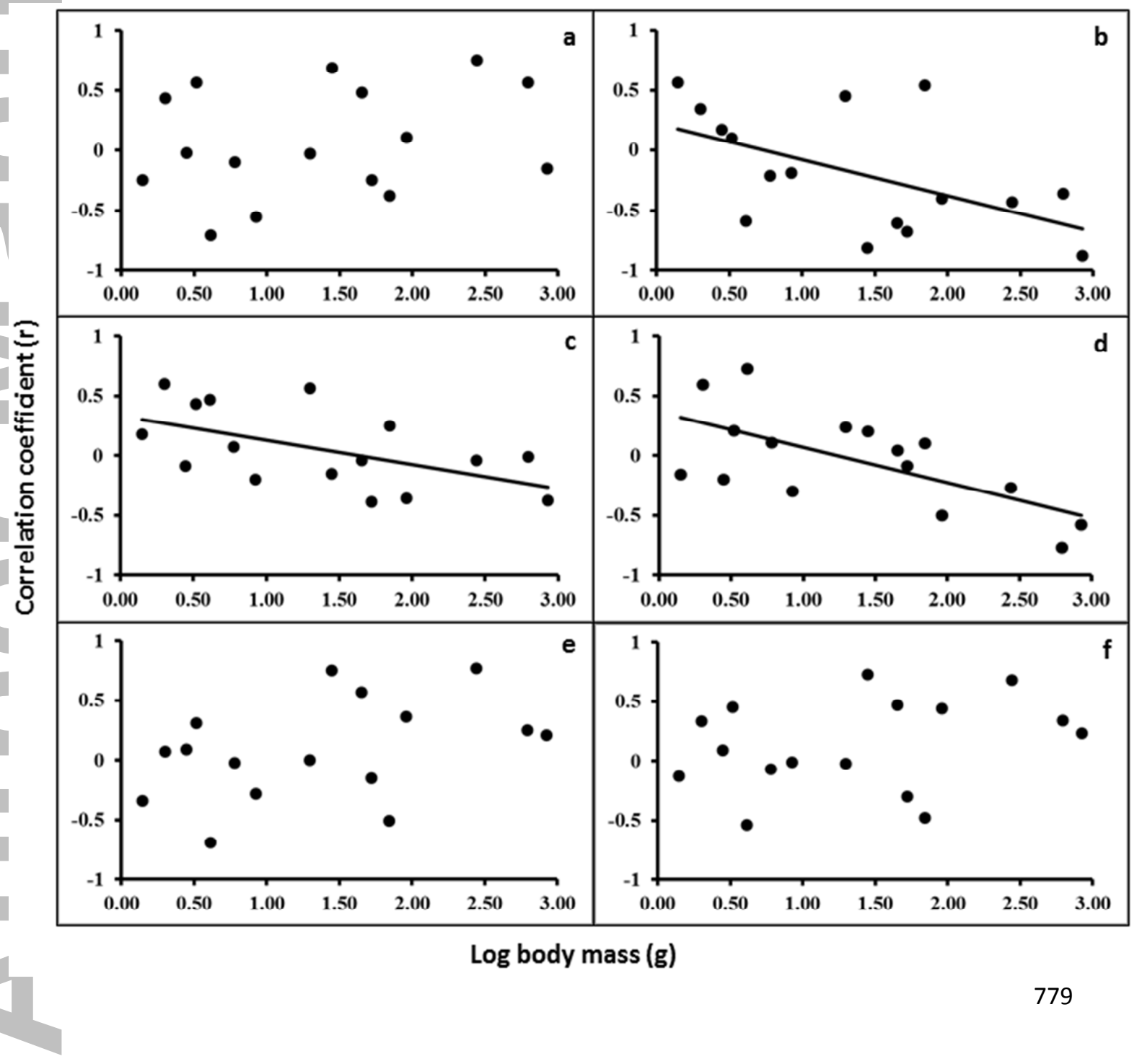


Figure 3. The relationship between the absolute value of the correlation coefficient (r) 780 of body length (mm; SVL for lizards, total length for snakes, see text) against predator 781 richness (a) and competitor richness (b) and the log mean body mass (g) of each $\quad 782$ species.

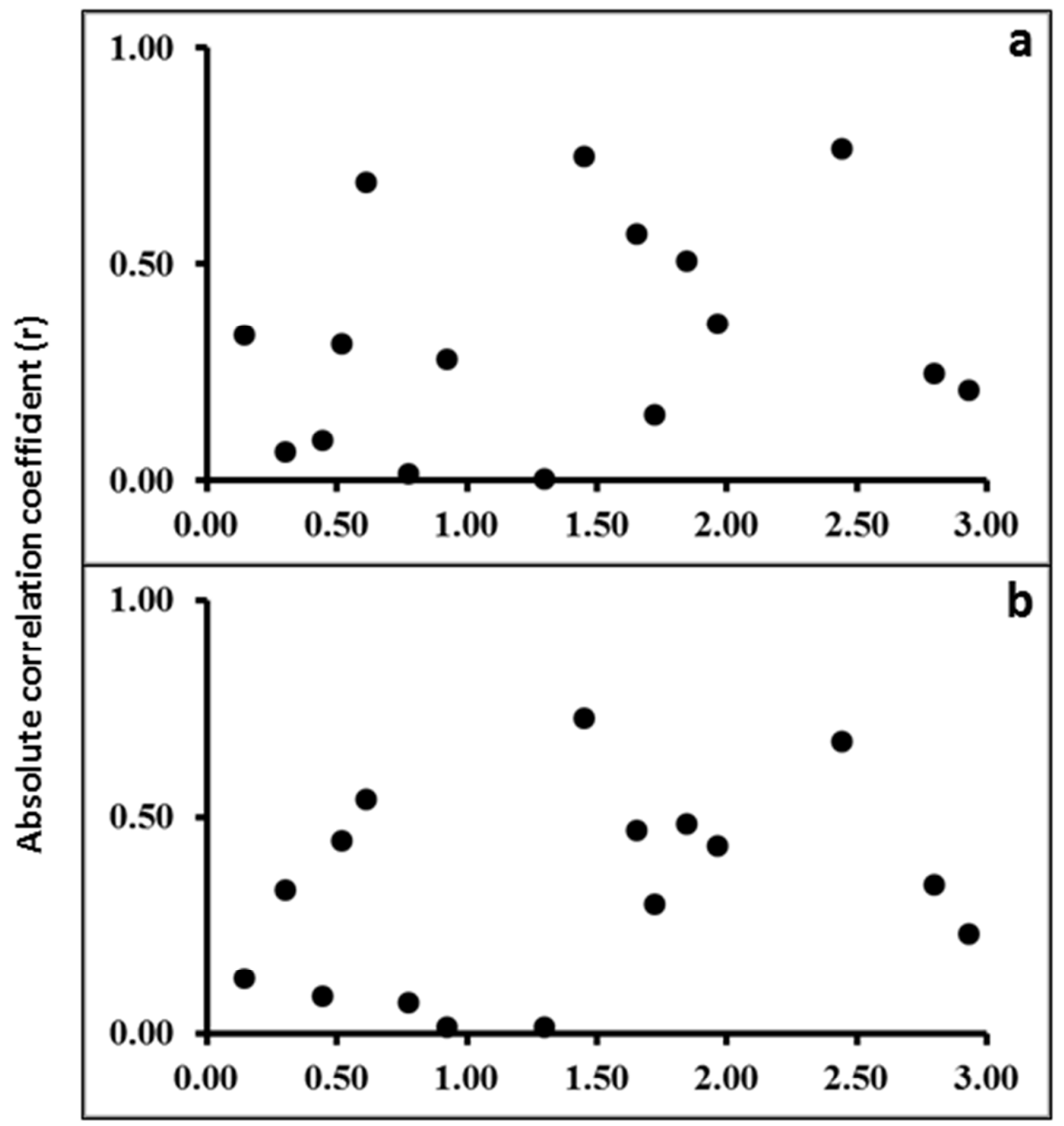

Log body mass (g) 


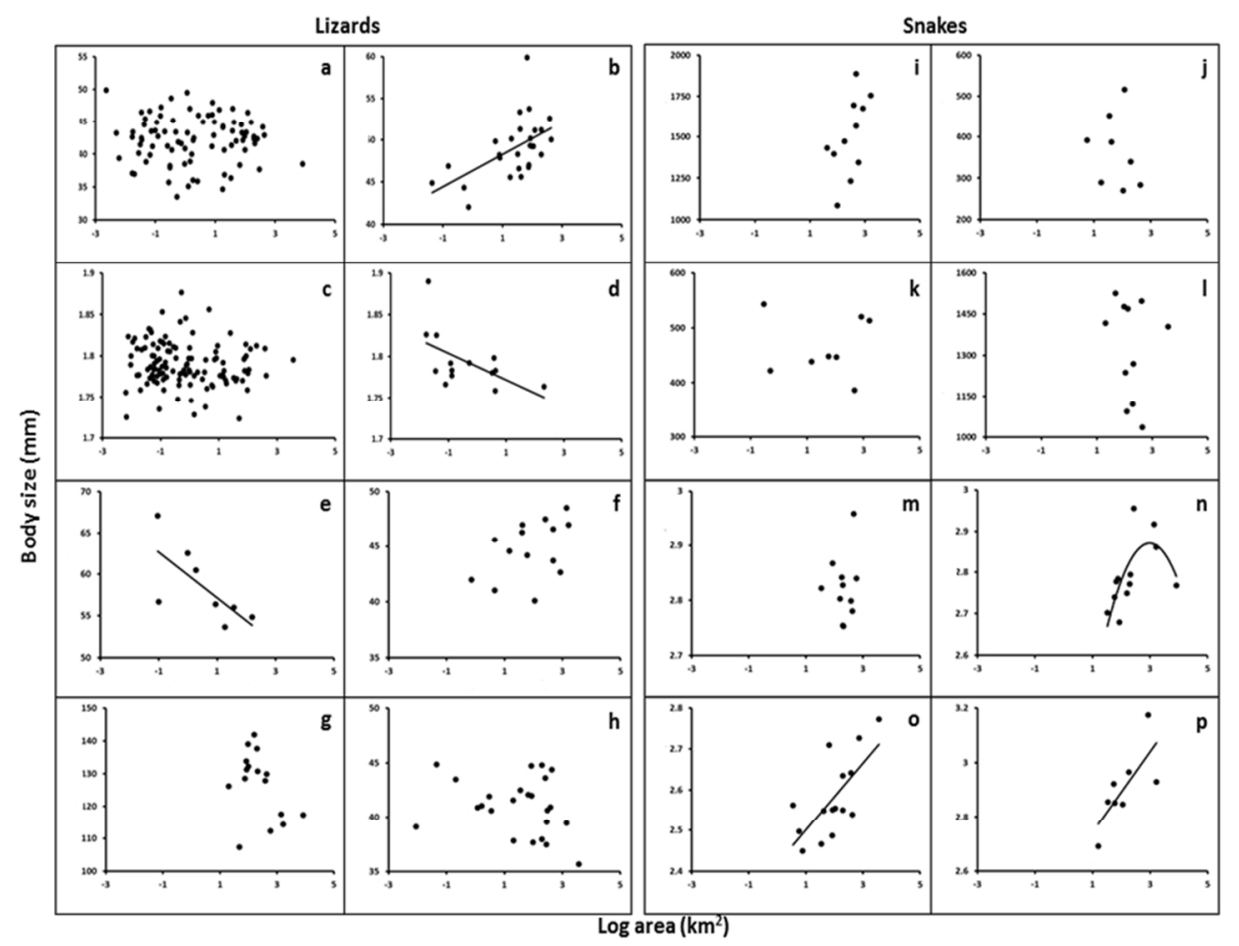

Figure 1. Body size as a function of island area: a - Mediodactylus kotschyi; b - Hemidactylus turcicus; c Podarcis erhardii; $d$ - Podarcis gaigeae; e - Podarcis milensis; $f$ - Ophisops elegans; $g$ - Lacerta trilineata; $h$ - Ablepharus kitaibelii; i -Dolichophis caspius; $j$ - Eryx jaculus; $k$ - Eirenis modestus; I - Elaphe quatuorlineata; $\mathrm{m}$ - Natrix natrix; $\mathrm{n}$ - Telescopus fallax; $\mathrm{o}$ - Vipera ammodytes; $\mathrm{p}$ - Vipera xanthina. Body size index is: SVL for species a, b, e, f, g, h; Log SVL for species c, d; Total length for species i, j, k, l; Log total length for species $m, n, o$, p. Full trend lines indicate a significant relationship $(p<0.05)$.

$81 \times 60 \mathrm{~mm}(300 \times 300 \mathrm{DPI})$ 


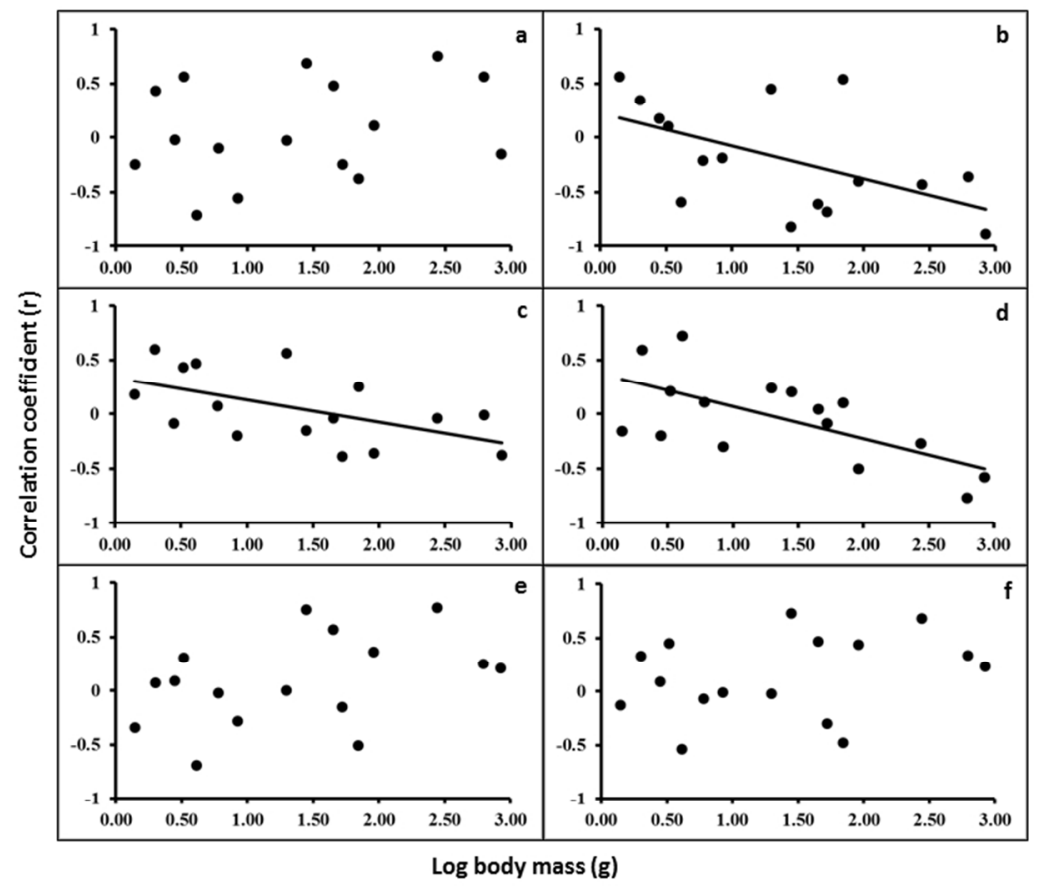

Figure 2. The relationship between the correlation coefficient ( $r$ ) of body length ( $\mathrm{mm}$; SVL for lizards, total length for snakes, see text) against each predictor variable and the log mean body mass ( $\mathrm{g}$ ) of each species.

Panels show: a - log island area $(\mathrm{km} 2) ; \mathrm{b}$ - distance from the mainland $(\mathrm{km})$; c - log distance from the closest larger island $(\mathrm{km})$; $\mathrm{d}$ - log time since isolation (years); e - predator richness; f - competitor richness. $n=16$ species in all cases. Trend lines are shown only if they are statistically significant.

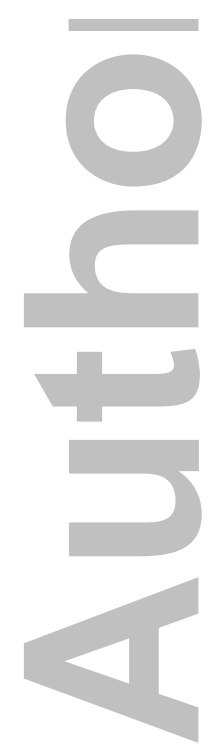

$81 \times 60 \mathrm{~mm}(300 \times 300$ DPI $)$ 


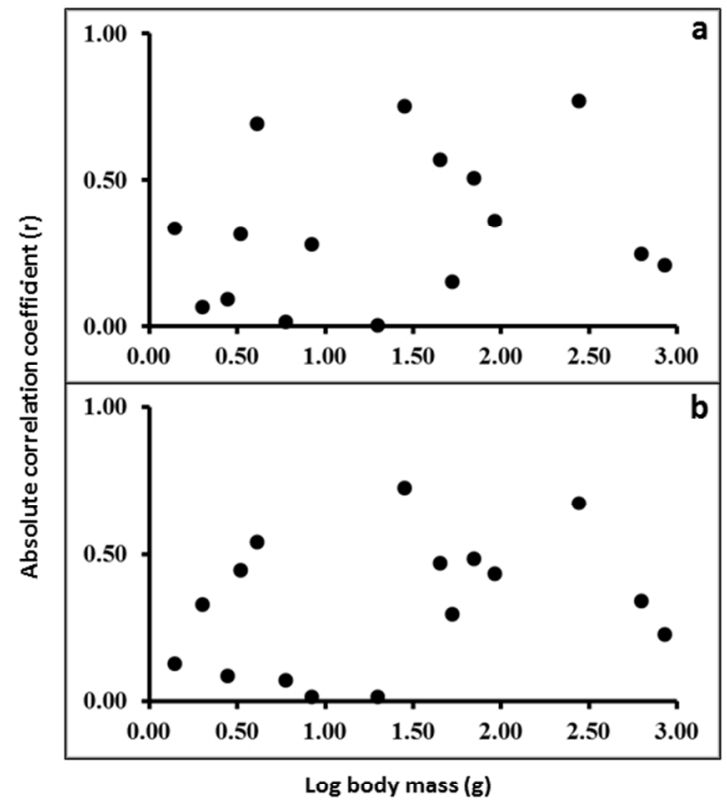

Figure 3. The relationship between the absolute value of the correlation coefficient $(r)$ of body length ( $\mathrm{mm}$; SVL for lizards, total length for snakes, see text) against predator richness (a) and competitor richness (b) and the log mean body mass $(\mathrm{g})$ of each species.

$81 \times 60 \mathrm{~mm}(300 \times 300 \mathrm{DPI})$ 